\title{
Criterios de agravación de la pena en los delitos de producción, difusión y almacenamiento de pornografía infantil*
}

\author{
Luis Rodríguez Collao**
}

\begin{abstract}
RESUMEN
El trabajo aborda los delitos de producción, difusión, adquisición y almacenamiento de pornografía infantil, desde una perspectiva estrictamente analítica. Por ello, prescindiendo de cualquier juicio crítico acerca de la procedencia de abordar legislativamente esas conductas o acerca de la forma en que el legislador chileno ba procedido en esta materia, el trabajo se circunscribe a una de las varias dificultades que plantean estos delitos: la aplicación respecto de ellos de los criterios de agravación de la pena que el Código Penal contempla para la generalidad de los delitos y de los criterios previstos para los delitos que atentan contra la integridad sexual. Entre ellos, alevosía, premeditación, pluralidad de autores, pago u oferta de una retribución, trato ignominioso y abuso de confianza.
\end{abstract}

Pornografía infantil - agravantes - indemnidad sexual

\section{Aggravating factors for crimes of production, dissemination and storage of child pornography}

\begin{abstract}
This article deals with the crimes of production, distribution, purchase and storage of child pornography, from a strictly analytical point of view. Therefore, regardless of any critical considerations about either the appropriateness of addressing these bebaviours legislatively or the way in which the Chilean legislature has proceeded with this matter, the work is limited to one of the several difficulties posed by these crimes: the application of the general factors to aggravate punishment provided by the Chilean Criminal Code and special factors regarding crimes against sexual integrity. These include ambush, premeditation, plurality of perpetrators, payment or remuneration offer, ignominious treatment and breach of trust.
\end{abstract}

Child pornography - aggravating factors - sexual indemnity

* Este trabajo fue elaborado como parte del proyecto de investigación FONDECYT N ${ }^{\circ} 1121195$, cuya unidad ejecutora es el Departamento de Derecho Penal y Derecho Procesal Penal de la Facultad de Derecho de la Pontificia Universidad Católica de Valparaíso.

** Abogado, Doctor en Derecho, profesor de Derecho Penal en la Pontificia Universidad Católica de Valparaíso, Chile. Correo electrónico: 1rodrigc@ucv.cl

Artículo recibido el 15 de marzo de 2013 y aceptado para su publicación por el Comité Editorial el 29 de mayo de 2013. 


\section{INTRODUCCIÓN}

$\mathrm{E}$ 1 texto original del Código Penal no contemplaba ningún delito relativo a la utilización de menores en la elaboración de material pornográfico ni a la difusión de esta clase de material. El único delito que captaba una conducta relativamente próxima a aquellas era el contemplado en el artículo 374, que hasta hoy se refiere a la venta, distribución o exhibición de materiales contrarios a las buenas costumbres, el que no hace distinción acerca de si en ellos se han utilizado menores de edad o adultos.

En la actualidad, sin embargo, el Código Penal contempla tres figuras delictivas que están estrechamente vinculadas con la pornografía infantil:

a) El artículo 366 quinquies, que sanciona al que participare en la producción de material pornográfico, cualquiera sea su soporte, en cuya elaboración hubieren sido utilizados menores de dieciocho años.

b) El artículo 374 bis inciso primero, que castiga a quien comercializare, importare, exportare, distribuyere, difundiere o exhibiere material pornográfico, cualquiera sea su soporte, en cuya elaboración hayan sido utilizados menores de dieciocho años.

c) El inciso segundo del mismo artículo 374 bis, que sanciona a quien maliciosamente adquiriere o almacenare material pornográfico, cualquiera sea su soporte, en cuya elaboración hayan sido utilizados menores de dieciocho años.

Por su parte, el inciso $2^{\circ}$ del artículo 366 quinquies dispone que para los efectos de las tres disposiciones recién mencionadas "se entenderá por material pornográfico en cuya elaboración hubieren sido utilizados menores de dieciocho años, toda representación de estos dedicados a actividades sexuales explícitas, reales o simuladas, o toda representación de sus partes genitales con fines primordialmente sexuales o toda representación de dichos menores en que se emplee su voz o imagen, con los mismos fines".

Este esquema normativo que en lo medular quedó fijado por las leyes $\mathrm{N}^{0} 19.927$, de 2004, y No 20.526, de 2011, se inserta dentro del Título VII del Libro II del Código Penal, cuyo epígrafe es: "Crímenes y delitos contra el orden de las familias, contra la moralidad pública y contra la integridad sexual".

Dentro de las múltiples dificultades que plantean los delitos relativos a la pornografía infantil, este trabajo se ocupa de un tema bien específico: la aplicación respecto de ellos de los criterios de agravación de la pena que contempla el Código Penal, tanto de aquellos que están establecidos para el común de los delitos como de aquellos que han sido instituidos para el ámbito concreto de los delitos contra la integridad sexual. En consecuencia, no debe esperarse aquí una completa revisión de los aspectos dogmáticos de los delitos relativos a la pornografía infantil (salvo lo necesario para una adecuada comprensión del tema de los criterios de conmensuración de la pena), ni una exposición crítica acerca de la conveniencia y excelencia de su consagración. 


\section{ANÁlisis DE LOS TIPOS DELICTIVOS}

\subsection{Producción de material pornográfico infantil}

La conducta sancionada aparece descrita como participar en la producción de material pornográfico, con utilización de personas menores de dieciocho años. Como puede apreciarse, lo sancionado no es la realización de ciertos actos con intervención del menor, lo que eventualmente puede ser captado por otros tipos (por ejemplo, violación, estupro o abuso sexual), sino la elaboración de un registro de la actividad desplegada por el menor. Este registro, como lo reconoce el propio artículo 366 quinquies, puede quedar plasmado en cualquier soporte, ya sea papel, magnético o digital ${ }^{1}$; y la representación podrá consistir en fotografías, dibujos y grabaciones visuales o auditivas ${ }^{2}$.

Es claro que basta con que el sujeto intervenga en la confección del material, sin que sea necesario que efectivamente lo haya producido, o que sea él quien utilizara al menor $^{3}$. Se subsume, entonces, no solo la conducta de aquel que capta las imágenes de carácter pornográfico y que, en estricto rigor, es quien utiliza al menor, sino también la de todo aquel que colabore en el proceso necesario, tanto para la obtención de dichas imágenes (piénsese, por ejemplo, en el sujeto encargado de la iluminación en el rodaje de una película pornográfica) como para la elaboración definitiva del material pornográfico, por ejemplo, montaje, edición, impresión, etc. ${ }^{4}$, aun cuando no haya contado con la presencia física del menor ${ }^{5}$.

Lo que se debe producir en esta actividad es material pornográfico infantil, el que es definido por el artículo 366 quinquies como todo aquel que exhiba a menores de dieciocho años realizando actividades sexuales explícitas, reales o simuladas, o bien que muestre las partes genitales del menor con fines primordialmente sexuales, o que utilice la voz o imagen de los menores con estos mismos fines ${ }^{6}$.

${ }^{1}$ Incluso puede ser un rollo de fotografía aún no revelado. Sentencia del Tribunal de Juicio Oral en lo Penal de Rancagua, de fecha 14 de noviembre de 2005, Rol 132-2005.

${ }^{2}$ Cfr. Molina Cantillana, R., Delitos de pornografía infantil, Librotecnia, Santiago, 2008, pp. 64-65.

${ }^{3}$ Cox Leixelard, J. P., "Los delitos de producción, adquisición y tenencia maliciosa de material pornográfico como figuras expansivas del Derecho Penal”, en Revista de Derecho de la Pontificia Universidad Católica de Valparaíso, XXVI, 2005, I, p. 152.

${ }^{4}$ Molina Cantillana, R., Delitos de pornografía infantil, cit., p. 63.

5 Así también lo estima De la Fuente Jiménez, C., Delitos de pornografía infantil, Legal Publishing, Santiago, 2008, p. 116. Sin embargo, será necesario que el menor tenga un cierto nivel de protagonismo dentro del conjunto de la producción. En este sentido, entre otros, Sáinz-Cantero, J. "Delitos contra la libertad e indemnidad sexual", en Morillas Cueva (coord.), Sistema de derecho penal español, parte especial, Dykinson, Madrid, 2011, pp. 279-280.

${ }^{6}$ Una sentencia del tribunal de juicio oral en lo penal de Valparaíso establece que son tres los criterios que orientan la calificación de pornografía de determinadas representaciones: a) ausencia de contenido ideológico, esto es, que la muestra eleve la sexualidad a una meta en sí misma, desconectada de una elaboración científica, artística o pedagógica como lo sería la muestra de los órganos genitales, por ejemplo, en una clase relativa a la reproducción; b) tendencia necesaria a la excitación sexual, siendo este un elemento decisivo al momento de determinar o de calificar la reproducción, y tal circunstancia debe haber sido buscada por el agente, puesto 
El tipo es de sujeto activo indiferente, por tanto cualquier persona puede tomar parte en la producción de material pornográfico. El sujeto pasivo, en cambio, debe ser un menor de edad, sin distinción etaria, independiente de su sexo.

En relación con el fundamento de la punición, para algunos el bien jurídico protegido es la libertad sexual, en su aspecto negativo, entendido como el derecho de la persona a no verse involucrada, sin su consentimiento, en un contexto sexual por un tercero ${ }^{7}$. Para Politoff, Matus y Ramírez, por su parte, el bien jurídico protegido depende de la edad de la víctima, ya que si esta es menor de catorce años, lo que se está protegiendo es la indemnidad sexual; en cambio, si la víctima es menor de edad, pero mayor de catorce años, el bien jurídico protegido sería la libertad sexual, ya que en este caso el legislador ha reconocido la capacidad de estos menores de autodeterminarse sexualmente ${ }^{8}$.

Por último, otro sector de la doctrina, acertadamente según mi opinión, plantea que el bien jurídico protegido es la indemnidad sexual del menor, entendida como el derecho de las personas a no verse involucradas en un contexto sexual, en atención al daño físico, psíquico o emocional que tal experiencia puede ocasionar en el común de los seres humanos ${ }^{9}$. En un sentido análogo, la Corte de Apelaciones de Concepción ha estimado que lo que se protege con el artículo 366 quinquies es la indemnidad sexual, la cual es definida como el derecho del menor a desarrollar su sexualidad en forma normal y natural sin interferencia de hechos que por su naturaleza anormal o desviada tengan la capacidad real o potencial para pervertir, corromper o impedir dicho desarrollo ${ }^{10}$.

\subsection{Difusión de material pornográfico}

La conducta sancionada aparece descrita como comercializar, importar, exportar, distribuir, difundir o exhibir material pornográfico en cuya elaboración hayan sido

que una fotografía, por ejemplo, no basta con que cause excitación en determinado sujeto sino que requiere, para ser calificada de pornográfica, que esta se haya realizado con el objetivo preciso de causar excitación sexual y c) la concurrencia de un elemento valorativo, cual es, que dicha representación exceda o sobrepase lo que generalmente en la sociedad es aceptable como decente en el ámbito sexual. Considerando séptimo, sentencia del tribunal de juicio oral en lo penal de Valparaíso, de fecha 14 de mayo de 2010, Rol 12-2010.

${ }^{7}$ Aguilar Aranela, C., Delitos sexuales, $2^{\text {a }}$ edición, Editorial Metropolitana, Santiago, 2012, p. 163. En un sentido, análogo Oxman Vilches, N., Libertad sexual y Estado de Derecho en Chile, Librotecnia, Santiago, 2007 , pp. 156 y 157, quien, aun cuando postula que lo protegido es la libertad sexual, estima que el consentimiento es inválido, ya que carece de la capacidad para comprender el sentido y trascendencia de la decisión en este ámbito. La edad se eleva debido a la mayor complejidad que implica la comprensión del ejercicio público de la sexualidad.

${ }^{8}$ Politoff, S., Matus, J. P., Ramírez, M. C., Lecciones de derecho penal. Parte especial, Editorial Jurídica de Chile, Santiago, 2005, p. 279. Un planteamiento similar formulan, en la doctrina española, Serrano Gómez, A., Serrano Maíllo, A., Derecho penal. Parte especial. 16a ed., Dykinson, Madrid, 2011, p. 252. En el mismo sentido, De la Fuente Jiménez, C., Delitos de pornografía infantil, cit., pp. 107 y 140. Solo como atentado contra la indemnidad sexual lo concibe Garrido Montt, M., Derecho Penal. Parte especial, $4^{\mathrm{a}}$ ed., Editorial Jurídica de Chile, Santiago, 2010, p. 338.

9 Ragués i Vallès, R., "Delitos contra la libertad e indemnidad sexuales”, en Silva Sánchez (dir.): Lecciones de derecho penal. Parte especial. $3^{\mathrm{a}}$ ed., Atelier, Barcelona, 2011, p. 136.

${ }^{10}$ Sentencia de la Corte de Apelaciones de Concepción, de fecha 12 de mayo de 2006, Rol 201-2006. 
utilizados menores de dieciocho años; todas las cuales, en realidad, pueden ser englobadas en los conceptos genéricos de traficar y difundir ${ }^{11}$. A pesar que la mayoría de los términos que utiliza el tipo tienen un significado mercantil, esto no obsta a que el tráfico de pornografía infantil sea efectuado a título gratuito o sin perseguir fines de lucro, ello es así, básicamente, porque el menor puede resultar afectado cualquiera sea la modalidad que asuma la puesta en circulación del material pornográfico ${ }^{12}$. Por su parte, el artículo 374 ter establece que dichas conductas se entenderán cometidas en Chile cuando se realicen a través de un sistema de telecomunicaciones al que se tenga acceso desde territorio nacional, lo cual es una referencia a las comunicaciones que se desarrollan a través de internet, las que serán sancionadas cuando se tenga acceso a ellas desde un equipo ubicado, aun temporalmente, en Chile.

El objeto material de este delito es idéntico al del delito anterior y consiste en el registro o material pornográfico obtenido con utilización del menor. Tampoco existen diferencias en relación con los sujetos, sin embargo se han planteado dudas acerca de la responsabilidad que tendrían las personas encargadas de los sitios en internet donde se trafica o difunde material pornográfico. En estos casos, a dichas personas no les cabría responsabilidad por el mero hecho de administrar o proveer tales servicios; salvo, por cierto, que ellos mismos suban material pornográfico infantil a los sitios de los que están a cargo ${ }^{13}$.

No existe consenso acerca del bien jurídico protegido por este delito, siendo muy común el planteamiento de que él protege a los menores frente a nuevos actos de elaboración de material pornográfico, ya que si existe una mayor demanda de estos productos, mayor deberá ser el volumen de material producido. Así lo estima una sentencia del Juzgado de Garantía de Santiago al señalar que "claramente aparecen dos justificaciones para la punición de las conductas ahí descritas (comercializar, exportar, etc.), por un lado la creación de una demanda de consumo pornográfico pone en peligro a los menores eventualmente utilizables en su producción y por otro el tráfico de imágenes pornográficas erosiona el respeto por la indemnidad sexual del menor"14. Por su parte, Politoff, Matus y Ramírez estiman que lo protegido en este tipo es la moralidad pública, y muy indirectamente la indemnidad sexual de los menores utilizados, que es afectada directamente solo por quienes elaboran el material pornográfico ${ }^{15}$.

Según mi opinión, lo que intenta proteger este delito es específicamente la intimidad del menor, único bien que podría resultar afectado. Ello en atención a que el tipo no

${ }^{11}$ Molina Cantillana, R., Delitos de pornografía infantil, cit., p. 86.

12 El Código Penal español en el artículo 189, número 3, letra c, contempla como tipo agravado el que los hechos son de especial gravedad atendiendo al valor económico del material pornográfico.

${ }^{13}$ En este sentido, De la Rosa Cortina, J. M., Los delitos de pornografía infantil. Aspectos penales, procesales $y$ criminológicos, Tirant lo Blanch, Valencia, 2011, p. 208, quien señala que los proveedores de acceso a internet que actúan proporcionando servicios de webhosting no tienen obligación de fiscalizar los contenidos de las páginas ni mucho menos de los mensajes de e-mail que se envían a través de su sistema.

${ }^{14}$ Sentencia del juzgado de garantía de Santiago, de fecha 21 de abril de 2006, Rol 680-2005.

15 Politoff, S., Matus, J. P., Ramírez, M. C., Lecciones de derecho penal. Parte especial, cit., p. 287. 
supone ninguna forma de contacto con la víctima, ni existe otro riesgo adicional para ella, pues el material ya está confeccionado al momento en que se ejecutan las conductas delictivas $^{16}$.

\subsection{Adquisición y almacenamiento de material pornográfico}

La conducta sancionada en este caso es la de adquirir o almacenar, maliciosamente, material pornográfico producido con utilización de menores de edad.

Un sector de la doctrina considera que ambas conductas pueden estar encaminadas, indistintamente, a un consumo personal o a su circulación en el mercado. A favor de este planteamiento puede invocarse que en la discusión del proyecto de ley se propuso sancionar el almacenamiento solo cuando se hiciese con ánimo de comercializar el material, pero luego dicha referencia fue eliminada, lo que transformó en innecesario aquel requerimiento ${ }^{17}$. También ha sido exigido por algunos tribunales que el almacenamiento tenga fines lúbricos, criterio que no comparto, porque una exigencia como esa requeriría una mención expresa en el texto de la ley, lo que no sucede en este caso ${ }^{18}$. Más aún si se considera que un ánimo de esa índole sí aparece exigido en otras figuras delictivas del mismo grupo, como sucede en el artículo 366 quáter del C. Penal.

Otra corriente de opinión considera, acertadamente, que la conducta de almacenamiento de material pornográfico debe ser interpretada sistemáticamente, consultando el tenor de otros preceptos que se refieren a la misma materia, particularmente el artículo $3^{\circ}$ $N^{o} 1$ letra c) del Protocolo Facultativo de la Convención sobre los Derechos del Niño relativo a la Venta de Niños, la Prostitución Infantil y la Utilización de Niños en la Pornografía ${ }^{19}$, que obliga a los Estados partes a sancionar en su ordenamiento jurídico las conductas de "producir, distribuir, divulgar, importar, exportar, ofrecer, vender o

${ }^{16}$ De esta misma opinión, Aguilar Aranela, C., Delitos sexuales, cit., p. 170, y Molina Cantillana, R., Delitos de pornografía infantil, cit., p. 83. En un sentido análogo Orts Berenguer, E., "Delitos contra la libertad e indemnidad sexuales”, en Vives Antón et al., Derecho penal. Parte especial. $3^{\text {a }}$ ed., Tirant lo Blanch, Valencia, 2010, p. 297.

${ }_{17}$ Boletín 2906-07, p. 39. Künsemüller, C., "Delitos de pornografía infantil”, en Gaceta jurídica, $\mathrm{N}^{\circ} 273$, 2003, p. 11, opinaba, cuando esta ley estaba aún en discusión, que la conducta debería estar subjetivamente orientada a un destino o finalidad posterior del material pornográfico (tráfico), cuyo empleo podría representar materialmente una lesión (al menos un peligro) para los bienes jurídicos que se busca proteger, ya que, de otro modo, se entrará en notorias contradicciones con las exigencias del principio de dañosidad social de conducta, en cuanto limitador del ius puniendi del Estado.

18 "La figura de almacenamiento de material pornográfico infantil contemplada en el inciso segundo del artículo 374 bis del Código Penal no exige que tal conducta se realice con la finalidad de comercializar dicho material, sino que es suficiente el acopio del mismo con fines lúbricos, y es por eso que la sanción para este delito es menor que la señalada para aquel que comercialice, importe, exporte, distribuya, difunda o exhiba ese material". Considerando sexto, sentencia de la Corte de Apelaciones de Concepción, de fecha 2 de noviembre de 2007, Rol 547-2007.

19 Aprobado por la Asamblea General de las Naciones Unidas en su resolución A/Res/54/263, de 25 de mayo de 2000; suscrito con la República de Chile el 28 de junio de dicho año y promulgado el 8 de agosto de 2003 . 
poseer, con los fines antes señalados, material pornográfico en que se utilicen niños....”. En otras palabras, según el instrumento internacional que sirvió de base a la enmienda legal del año 2004, el castigo no se hace extensivo a cualquier forma de posesión de material pornográfico, sino exclusivamente a aquella que tiene por objeto comercializar o hacer circular dicho material.

Por último, no debemos olvidar que aquellos países que han optado por sancionar el almacenamiento de material pornográfico para uso personal han tenido que establecerlo de modo expreso, como sucede en España, a raíz de la modificación de que fue objeto el artículo $189, \mathrm{~N}^{\circ} 1$, letra b) del Código Penal de ese país ${ }^{20}$.

Por adquirir debemos entender, como es costumbre, el hacer propia una cosa, con ánimo de señor y dueño. Por tanto no quedan incluidas las situaciones donde se recibe pornografía infantil, por ejemplo al correo electrónico, sin que haya mediado una solicitud, si esta es eliminada de inmediato. Lo mismo ocurre si se recibe como correo no deseado o spam dicho material y esto se desconoce por parte del propietario de la cuenta de correo. Al respecto, no debemos olvidar que lo sancionado no es la mera contemplación de las imágenes ${ }^{21}$, motivo por el cual cabe afirmar que la mera consulta a una página de pornografía infantil en la red no queda incluida entre las hipótesis del artículo 374 bis del Código Penal ${ }^{22}$.

En el caso de la conducta de almacenar, el número de imágenes, videos u otro soporte no está determinado previamente y será el juez quien establezca si existe o no almacenamiento en cada caso $^{23}$. Con todo, para la Corte Suprema, no es relevante la cantidad de material encontrado en poder de una persona para configurar el delito de almacenamiento de material pornográfico infantil ${ }^{24}$.

Respecto del bien jurídico protegido, los autores proponen también una amplia gama de posibilidades, pero con énfasis en un decidido cuestionamiento acerca de los fundamentos de esta figura ${ }^{25}$. Así, para Molina Cantillana, el bien jurídico protegido no sería la dignidad del menor ${ }^{26}$, que él plantea como objeto de protección para el caso de las demás conductas sancionadas, porque esta ya fue vulnerada en las etapas anteriores

${ }^{20}$ Orts Berenguer, E., "Delitos contra la libertad e indemnidad sexuales”, cit., p. 301; Sáinz-Cantero, J. "Delitos contra la libertad e indemnidad sexual", cit., pp. 279-280.

${ }^{21}$ Cugat Mauri, M., "Prostitución y corrupción de menores e incapaces”, en Álvarez García (dir.): Derecho penal español. Parte especial, Tirant lo Blanch, Valencia, 2011, p. 703.

${ }^{22}$ De la Fuente Jiménez, C., Delitos de pornografía infantil, cit., p. 183. En este mismo sentido, De la Rosa Cortina, J. M., Los delitos de pornografía infantil, cit., p. 100.

${ }^{23}$ Se sustituyeron las palabras del proyecto original "tuviere o poseyere" por "almacenare" para exculpar a quienes posean material pornográfico en escasa cantidad. Boletín 2906-07, p. 39.

${ }^{24}$ Sentencia de la Corte Suprema, de fecha 18 de agosto de 2009, Rol 3557-09, considerando trigésimo. En el mismo sentido, Aguilar Aranela, C., Delitos sexuales, cit., p. 177.

${ }^{25}$ Para Sánchez Pecarevic, Claudio (2010), Delito de almacenamiento de pornografía infantil, Santiago: Librotecnia, p. 164, por ejemplo, el castigo de la adquisición y almacenamiento de material pornográfico para fines de consumo privado representa una intromisión flagrante en la esfera de libertades individuales de las personas, que en otros ámbitos de la represión penal ha dado suficientes muestras de ineficiencia funcional.

${ }^{26}$ Aguilar Aranela, C., Delitos sexuales, cit., p. 170, plantea como bien jurídico en estos supuestos la dignidad del menor. 
de difusión. El consumidor, plantea, no hace otra cosa que observar el material ya confeccionado, por ello lo único que podría plantearse como bien jurídico protegido sería la moral sexual colectiva, castigando más bien un vicio moral como es la inclinación por la pornografía infantil. Por tal motivo, concluye sosteniendo derechamente la inconstitucionalidad de esta disposición, la que no consagraría ningún bien jurídico digno de protección, atentando entonces contra el principio de lesividad ${ }^{27}$.

Para De la Rosa, el delito de posesión de pornografía infantil no supone ataque contra la libertad o indemnidad sexual, estructurándose como tipo de peligro, en cuanto la existencia de demanda y oferta genera el incremento de la producción. Continúa este autor afirmando que igualmente se ataca la dignidad de la infancia en general ${ }^{28}$. Así también lo plantea una sentencia de la Corte Suprema que discurriendo sobre el objeto de tutela del delito del inciso segundo del artículo 374 bis estima que "en tal evento el bien jurídico es la dignidad de los menores, toda vez que se contribuye con la conducta sancionada al mantenimiento y expansión de una nueva y degradante industria, que tiene como presupuesto y objeto la comisión de gravísimos delitos sexuales contra niños y niñas, lo que fue, además, el parecer del legislador chileno en el origen del proyecto de la Ley $\mathrm{N}^{\circ}$ 19.927, impidiendo la proliferación de la pornografía para lograr la disminución de su demanda" 29 .

Según mi opinión, como ya lo he señalado detenidamente en otro lugar, no corresponde considerar la dignidad humana como bien jurídico protegido en este ni en ningún otro sector del ordenamiento penal ${ }^{30}$. En realidad, el único fundamento admisible para esta figura es considerarla como un atentado contra la intimidad sexual, siempre que por su naturaleza el material adquirido o almacenado sea susceptible de provocar una lesión a dicho interés; y si así no fuera, solo cabría pronunciarse por la inaplicabilidad del precepto.

\section{AgraVANTES ESPECÍfICAS DE LOS DELITOS CONTRA LA INTEGRIDAD SEXUAL}

\subsection{Relación de dependencia jurídica o moral de la víctima al autor}

El artículo 368 del Código Penal concede efecto agravatorio al hecho de ser el autor del delito "autoridad pública, ministro de un culto religioso, guardador, maestro, empleado o encargado por cualquier título o causa de la educación, guarda, curación o cuidado del ofendido".

27 Molina Cantillana, R., Delitos de pornografía infantil, cit., pp. 104-106; Morillas Fernández, D., Análisis dogmático y criminológico de los delitos de pornografía infantil, Dykinson, Madrid, 2005, p. 173; Cfr. Oxman Vilches, N., Libertad sexual y Estado de Derecho en Chile, cit., p. 224, y Sánchez Pecarevic, C., Delito de almacenamiento de pornografía infantil, cit., p. 169.

${ }^{28}$ De la Rosa Cortina, J. M., Los delitos de pornografía infantil, cit., pp. 58-59.

${ }^{29}$ Sentencia de la Corte Suprema, de fecha 18 de agosto de 2009, Rol 3557-09.

${ }^{30}$ Rodríguez Collao, L., "Honor y dignidad humana", cit., pp. 9 ss. 
En relación con el ámbito de aplicación de esta circunstancia, el propio artículo 368 lo limita a los delitos previstos en los párrafos $5^{\circ}$ y $6^{\circ}$ del título respectivo, remisión que, en principio, afecta a los tipos de violación (arts. 361 y 362), estupro (art. 363), sodomía (art. 365), abuso sexual (arts. 365 bis, 366, 366 bis, 366 quáter), producción de material pornográfico infantil (art. 366 quinquies), favorecimiento de la prostitución (art. 367), favorecimiento del tráfico de personas con fines sexuales (art. 367 bis) y obtención de servicios sexuales mediante precio (367 ter). No es aplicable, por el contrario, al delito de difusión de material pornográfico infantil ni a los de adquisición y almacenamiento de ese mismo material los que están tipificados en el artículo 374 bis, incisos primero y segundo, respectivamente, es decir, fuera del ámbito de aplicación de esta circunstancia.

El fundamento de esta agravante, como fluye claramente de su texto, es el hecho de encontrarse el autor en una posición más ventajosa para la ejecución del delito, en razón de que existe un vínculo -jurídico o moral- que lo une a la víctima y que deja a esta en una situación de dependencia respecto de aquel ${ }^{31}$. Para la configuración de la agravante, en consecuencia, no basta con que el autor esté investido de alguna de las cualidades que la norma menciona, sino que será preciso que el sujeto pasivo se halle efectivamente sujeto a la autoridad que aquellas confieren ${ }^{32}$. Asimismo, una interpretación contextual de la preceptiva que regula los delitos sexuales permite concluir que la circunstancia solo será aplicable en caso que el hechor haya abusado de la situación de privilegio en que se encuentra respecto de la víctima ${ }^{33}$; porque si este requisito es exigible para la configuración del hecho delictivo, cada vez que el tipo exige que esta se encuentre en una posición desventajosa -como ocurre en los delitos de violación, estupro, abuso sexual y favorecimiento de la prostitución-, con mayor razón habrá de exigirse lo mismo para decidir sobre la concurrencia de un elemento que solo incide en la graduación de la responsabilidad criminal.

Por tratarse de una circunstancia que supone la existencia de un vínculo previo entre el autor y el sujeto pasivo, cabe dentro de la categoría de las circunstancias personales y, por lo tanto, no se comunica a otras personas que hubieren intervenido en la ejecución del delito.

Pese a que el tema puede suscitar dudas, debe entenderse que los ascendientes de la víctima se encuentran incluidos en los términos que utiliza la disposición, siempre que los primeros estén efectivamente al cuidado de la segunda. Ello obedece a que, desde un punto de vista semántico, no hay ningún inconveniente para atribuir al padre o a la madre la condición de "encargado por cualquier título o causa de la educación, guarda o cuidado del ofendido". Por otra parte, no debe pensarse que el hecho de que los ascendientes sí figuran de modo expreso en la descripción de la agravante que contempla

${ }^{31}$ En un sentido análogo, Garrido Montt, M., Derecho penal, cit., III, p. 361.

32 De modo que no basta, por ejemplo, con que el autor sea ministro de algún culto religioso, sino que, además, la víctima tendrá que contarse entre las personas respecto de quiénes aquel ejerce su ministerio.

${ }^{33}$ Esta es la forma en que los autores y la jurisprudencia española entienden la circunstancia similar que contempla el Código Penal de aquel país. Por todos, Sáinz-Cantero, J. "Delitos contra la libertad e indemnidad sexual”, cit., p. 246, y Serrano Gómez, A., Serrano Maíllo, A., Derecho penal. Parte especial, cit., p. 222. 
el artículo 371 del Código Penal es un motivo para sostener que aquellos quedan excluidos de la circunstancia que contempla el artículo 368 del mismo Código, porque la diferencia entre estas dos agravantes no es la categoría de personas a quienes ellas se aplican, sino el papel que tales personas desempeñan: cómplices, en la primera; autores, en la segunda. Queda de manifiesto, en consecuencia, que la aplicación del artículo 368 a los ascendientes no importa vulnerar la garantía de determinación que va implícita en el principio de legalidad penal ${ }^{34}$.

Por último, los efectos de la circunstancia no son los comunes a toda agravante, sino los específicos que señala el inciso primero del artículo 368, es decir, que la pena se impondrá "con exclusión de su grado mínimo, si ella consta de dos o más grados, o de su mitad inferior, si la pena es un grado de una divisible”.

\subsection{Circunstancia agravante del artículo 371 del Código Penal}

Dispone este artículo que "los ascendientes, guardadores, maestros y cualesquiera personas que con abuso de autoridad o encargo, cooperaren como cómplices a la perpetración de los delitos comprendidos en los dos párrafos precedentes, serán penados como autores".

Esta circunstancia no es más que una simple reiteración de la agravante anterior, con la única diferencia de que en este caso los destinatarios de la norma no son los autores del hecho respectivo, sino quienes hubieren intervenido como cómplices. En consecuencia, tanto respecto del fundamento como de los requisitos y del campo de aplicación, cabe reiterar lo ya expresado en el acápite precedente. Asimismo, y por idéntica razón, no cabe una aplicación conjunta de las circunstancias contempladas en los artículos 368 y 371 del Código Penal.

Tomando en consideración lo dicho respecto del campo de aplicación, la agravante prevista en el artículo 371 del Código Penal, debemos concluir que ella no es aplicable a la figura de difusión de material pornográfico infantil ni a la de adquisición y almacenamiento de ese mismo material, por estar contempladas en el artículo 374 bis, incisos primero y segundo, respectivamente, que está fuera del ámbito de aplicación de esta circunstancia.

Además, si bien es cierto que la figura de producción de material pornográfico infantil está situada en el artículo 366 quinquies, es decir, dentro del ámbito de aplicación de la agravante que nos ocupa, forzoso es concluir que ella tampoco es aplicable respecto de aquel delito. Recordemos que la conducta sancionada en este caso consiste en participar en la producción de material pornográfico, y que al utilizar una fórmula tan amplia, el tipo

${ }^{34}$ De no aceptarse este planteamiento, resultaría que los ascendientes quedarían sujetos a un trato más ventajoso que el resto de las personas mencionadas en los artículos 368 y 371 . Porque, en efecto, si tales ascendientes no estuvieran incluidos en el primero de esos artículos, solo verían agravada su responsabilidad (al menos a este título) en caso de intervenir como cómplices, no así en el evento de comportarse como autores; en cambio, el resto de los destinatarios de la norma vería agravada su situación penal, tanto a nivel de autoría como de complicidad. 
no solo da cabida a quienes intervengan como autores de la producción, sino también a quienes se comportan como cómplices, limitándose a cooperar en el registro de la actividad pornográfica. En estas circunstancias, la aplicación de la agravante a quien interviene como cómplice implicaría una abierta transgresión del principio non bis in idem.

\section{Nuevas agravantes EN El Ámbito De LA CRIMINALidAd SEXUAL}

\subsection{Explicación general}

La Ley N $\mathrm{N}^{\circ}$ 20.480, publicada el 18 de diciembre de 2010, introdujo importantes modificaciones en el ámbito de los delitos de significación sexual, entre ellas la incorporación de un nuevo artículo 368 bis que pasó a contemplar dos nuevas agravantes aplicables a un segmento importante de los delitos recién mencionados: la agravante de alevosía y la de ser dos o más los autores del delito. Antes de entrar al examen particular de cada una de ellas, conviene revisar dos aspectos de carácter general.

El primero de ellos es el ámbito de aplicación de las nuevas agravantes, que, una vez más, aparece expresado con una referencia a los párrafos 5 y 6 del título VII del Libro II del Código Penal. Tomando como base este elemento, debemos concluir que las nuevas disposiciones son aplicables a los delitos de violación propia (art. 361), violación impropia (art. 362), estupro (art. 363), sodomía (art. 365), abuso sexual propio o directo (arts. 365 bis, 366, 366 bis y 366 ter), abuso sexual impropio o indirecto (art. 366 quáter), producción de material pornográfico infantil (art. 366 quinquies); favorecimiento de la prostitución (art. 367); favorecimiento del tráfico de personas con fines sexuales (art. 367 bis) y obtención de servicios sexuales mediante precio (art. 367 ter). En consecuencia, concentrándonos en el ámbito a que se refiere este trabajo, debemos concluir que las dos nuevas agravantes que introdujo el artículo 368 bis del Código Penal, solo son aplicables a la figura de producción de material pornográfico infantil y no lo son, en cambio, respecto de los delitos de difusión, adquisición y almacenamiento de ese mismo material.

Enseguida, cabe tener presente que las nuevas agravantes son aplicables sin perjuicio de lo dispuesto en el artículo 63 del Código Penal. Al respecto cabe recordar que la locución adverbial "sin perjuicio", como lo reconoce el propio Diccionario de la Lengua de la Real Academia Española, significa: “dejando a salvo” (en este caso, las disposiciones del mencionado artículo 63). De lo cual se infiere que las nuevas agravantes solo son aplicables a condición de que ellas no estén incluidas en las respectivas descripciones típicas y siempre que no sean de tal manera inherentes al delito, que sin la concurrencia de ellas aquel no pueda cometerse.

La aclaración legislativa es comprensible, pues basta examinar someramente la regulación de las figuras de los párrafos $5^{\circ}$ y $6^{\circ}$ del Título VII para comprobar que no son pocos los casos en que, por ejemplo, la alevosía ya ha sido contemplada por el legislador a modo de elemento típico. Sucede así en el delito de violación propia del artículo 361, donde todas las circunstancias de ejecución dan cuenta de un actuar de por sí alevoso. 
Asimismo, debido a las características de esta forma de delincuencia, será común hallar casos en que la circunstancia descrita resulte ser inherente a la ejecución del hecho ${ }^{35}$. Queda de manifiesto, así, que la operatividad del nuevo artículo 368 bis es bastante reducida.

\subsection{Alevosía}

En relación con el sentido y el alcance del término alevosía, es claro que este debe ser entendido aquí según el mismo significado que le atribuye el artículo 12, circunstancia primera, del Código Penal cuando señala que la agravante consiste en obrar a traición o sobre seguro. Actuar a traición según lo ha manifestado la Corte Suprema implica el ocultamiento de la intención verdadera del agente, presentando ante la víctima una situación con características distintas a las que realmente posee. Actuar sobre seguro, en cambio, significa crear o aprovechar oportunidades materiales que eviten todo riesgo a la persona del autor, sea que ese riego provenga de la posible reacción de la víctima o de terceros que la protegen ${ }^{36}$.

En otras palabras, como se desprende de la propia definición legal, la idea que subyace a la noción de alevosía es el estado de indefensión o de mayor vulnerabilidad del sujeto pasivo; o, para ser más exactos, el mayor desvalor que la ley le atribuye al estado de indefensión que es connatural a quien es víctima de una actuación alevosa. Desde el punto de vista del autor, está implícita la idea de aseguramiento de la ejecución del delito y la evitación de riesgos para sí mismo ${ }^{37}$. Tomando como base este planteamiento y considerando la forma en que tal estado puede procurarse, los autores suelen distinguir tres situaciones: a) alevosía súbita, en que el ataque se presenta como un acontecimiento sorpresivo y completamente inesperado para la víctima; b) alevosía proditoria, que se da cuando el sujeto pasivo enfrenta una situación de acecho o emboscada, y c) alevosía de prevalimiento, que se manifiesta cuando el autor aprovecha una situación de vulnerabilidad que padece la víctima ${ }^{38}$.

Desde este punto de vista, lo cierto es que en el ámbito de los delitos de significación sexual, la alevosía solo tiene sentido respecto de las figuras que implican ejercicio

35 Advierten esta situación Santibáñez Torres, M. E., Vargas Pinto, T., "Reflexiones en torno a las modificaciones para sancionar el femicidio y otras reformas relacionadas (Ley N $\mathrm{N}^{\circ}$ 20.480)", en Revista Chilena de Derecho, 1 (abril 2011, Santiago), 38, p. 203.

36 Sentencia de la CS de 28 de enero de 2003, Rol No 271-2003, Legal Publishing: 26174. Estos criterios son los mismos que fluyen de la forma en que la RAE define los términos que utiliza la definición legal de alevosía.

37 Gracia Martín, L., Vizueta Fernández, J., Los delitos de homicidio y de asesinato en el Código Penal español, Tirant lo Blanch, Valencia, 2007, p. 123.

${ }^{38}$ Cfr., entre otros, Arias Eibe, M., "La circunstancia agravante de alevosía”, en Revista Electrónica de Ciencia Penal y Criminología, 07-03, 2005, pp. 14-15; y Suárez-Mira Rodríguez, C., Manual de Derecho Penal. Parte especial, Civitas, Madrid, 2006, p. 68. Basadas en el derecho nacional, Cury, E., Derecho Penal. Parte General, $10^{a}$ edición ampliada, Editorial Universidad Católica de Chile, Santiago, 2011, pp. 516-520; Etcheberry, A.,

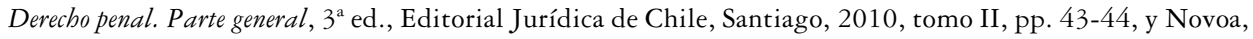

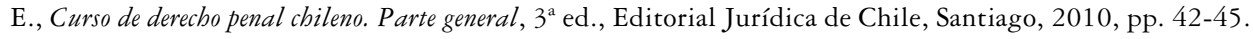


de violencia o intimidación, porque en las otras modalidades de ejecución del delito de violación -particularmente la enajenación mental, la privación de sentido y la incapacidad para oponerse- el estado de indefensión en que se encuentra la víctima es inherente a cada una de esas modalidades de ejecución y, por lo tanto, incompatible con aquella agravante, por expresa disposición del artículo 63 del Código Penal. Por cierto, las mismas consideraciones son aplicables respecto del delito de abuso sexual.

En virtud del principio de irrelevancia, tampoco resulta procedente aplicar la agravante respecto de los delitos de estupro, sodomía y obtención de servicios sexuales mediante precio, porque en todos estos casos el delito presupone la actuación voluntaria de la víctima; y tampoco en el delito de favorecimiento de la prostitución, porque este no involucra un contacto directo entre el autor y la víctima, en circunstancias que es de la esencia de la alevosía, por razones semánticas e históricas, que haya una actuación en contra de las condiciones físicas del individuo.

En el caso del delito de producción de material pornográfico infantil, si bien es imaginable la posibilidad de aplicar la alevosía, es necesario distinguir con toda nitidez entre los actos que son objeto de registro y los actos que implican elaboración del material. Son estos los que en esencia configuran aquel delito y son, por cierto, los que deben tomarse en consideración para apreciar la concurrencia de la alevosía (como así también de cualquier otra circunstancia). Ello, porque es perfectamente imaginable que los actos registrados sean alevosos, pero que no lo sean los actos que implican elaboración del registro y viceversa.

\subsection{Pluralidad de autores}

Respecto ahora de la agravante de pluralidad de intervinientes, recordemos que el nuevo artículo 368 bis se refiere a ella como "ser dos o más los autores del delito". En otras palabras, no bastará con intervenir en el delito, sino que será necesario hacerlo en calidad de autor. Lo cual desde ya descarta la posibilidad de aplicar la agravante en caso que el delito contemple la intervención, por ejemplo, de un autor y un partícipe. Sin embargo, como el artículo 15 del Código Penal, al tratar la autoría, no utiliza la fórmula "son autores", sino la fórmula, mucho más ambigua, de "se consideran autores", no basta con señalar que la actuación de un individuo aparece captada por dicho artículo, porque perfectamente podríamos estar frente a uno de aquellos casos -como ocurre con la instigación - en que una forma de participación ha sido asimilada a la autoría para efectos penales.

Por otra parte, sería del todo satisfactorio que la praxis judicial exigiera la presencia física de ambos intervinientes al momento de ejecutarse la conducta delictiva, como invariablemente lo exigen la doctrina y la jurisprudencia españolas frente a un texto muy similar al nuestro; aunque, por cierto, no es necesario que los dos intervinientes hayan tomado parte en la ejecución de la conducta principal del delito de que se trate ${ }^{39}$.

${ }^{39}$ Morales Prats, F., García Albero, R., "Delitos contra la libertad e indemnidad sexuales”, en Quintero Olivares (dir.), Comentarios a la parte especial del derecho penal, 9a ed. Aranzadi, Pamplona, 2011, p. 327. 
Al aplicar la agravante de pluralidad de autores es preciso ser muy cuidadoso, porque en muchos casos la existencia de más de un ejecutor es precisamente lo que permite dar por establecida la concurrencia de otros requisitos, como ocurre, por ejemplo, con la intimidación. En esos casos no será posible aplicar la agravante sin vulnerar el principio non bis in idem.

El fundamento del mayor desvalor que se atribuye a la actuación plural es, al igual que en la alevosía, el estado de indefensión en que se encuentra la víctima. De ahí que no sea posible aplicar esta agravante conjuntamente con la de alevosía.

Razonando específicamente acerca del delito de producción de material pornográfico infantil -único al cual podría resultar aplicable esta circunstancia por las razones que ya conocemos-, conviene formular dos precisiones: por una parte, que la posibilidad de apreciar la pluralidad de autores como agravante debe ser examinada en relación con la conducta que en esencia configura ese delito, sin considerar los actos que han sido objeto de registro (que eventualmente podrían dar lugar a la configuración de otros delitos) y sin considerar tampoco otras acciones que podrían quedar encasilladas dentro de los conceptos de difusión o de adquisición de aquel material; y, por otra parte, que en un número importante de los casos, como ya ha sido dicho, la pluralidad de intervinientes se presenta como inherente a la producción de material pornográfico, situaciones en las cuales no procede concederle efecto agravatorio, por expresa disposición del artículo 63 del Código Penal.

\section{Aplicabilidad de las agravantes del art. i 2 del Código Penal}

\subsection{Sobre la cláusula "delitos contra las personas"}

Uno de los puntos que ha suscitado polémica dentro de la preceptiva que el Código Penal destina a las agravantes, es el alcance que debemos atribuir a la cláusula "Delitos contra las personas", que aparece consignada en el artículo $12 \mathrm{~N}^{\circ} 1$, a propósito de la alevosía, y en el $\mathrm{N}^{0}$ 5, a propósito de la premeditación y del uso de astucia, fraude o disfraz. Como se sabe, la discusión gira en torno a si dicha cláusula se refiere a todos los delitos que atentan contra bienes jurídicos personales, cualquiera sea su ubicación; o si, por el contrario, ella alude exclusivamente a los delitos que aparecen tipificados dentro del Título VIII del Libro II del Código, cuyo epígrafe reza, precisamente, Crímenes y simples delitos contra las personas.

Una posición extensiva ${ }^{40}$ sostiene que es posible considerar como delitos contra las personas para estos efectos a cualquiera que incluya el desvalor de un atentado contra la vida o la integridad física de las personas, como sucede señaladamente con los delitos complejos.

${ }^{40}$ Cury, E., Derecho Penal., cit., pp. 518-519; Bullemore, V., Mackinnon, J., Curso de derecho penal chileno, LexisNexis, Santiago, 2005, tomo II, pp. 181-182. En cierta forma también Novoa, E., Curso de derecho penal chileno, cit., pp. 45-46, al menos respecto de la alevosía. 
En contra de este planteamiento han opinado durante los últimos años los profesores Ramírez Guzmán y Mera Figueroa ${ }^{41}$, a quienes en mi concepto les asiste toda la razón. Varias son, en efecto, las razones que pueden invocarse para circunscribir la cláusula "Delitos contra las personas" únicamente a las infracciones que se encuentren tipificadas dentro del Título VIII del Libro II.

En primer término, una razón de índole histórica, cual es que el Código Penal español que sirvió de modelo al nuestro no contenía una limitación como la que el artículo 12 impone a la alevosía y a la premeditación y que la decisión de incluirla fue adoptada por la Comisión Redactora en la sesión 122, cuando la redacción de ese Título se encontraba ya concluida.

En segundo lugar, desde la perspectiva de una interpretación sistemática del Código Penal que efectivamente considere la necesidad de que haya correspondencia y armonía entre las distintas partes que lo integran, resulta innegable el imperativo de atribuir a la cláusula "delitos contra las personas" que utiliza el artículo 12 el mismo significado que ella tiene en el epígrafe del Título VIII del Libro II.

Desde otra perspectiva, el criterio que aquí defendemos se funda en la necesidad de interpretar restrictivamente el artículo 12 del Código Penal, como efectivamente lo demanda el respeto del principio de legalidad, que se opone a interpretaciones extensivas o analógicas ${ }^{42}$. Esta exigencia es mucho más apremiante en el caso de las circunstancias modificatorias de responsabilidad penal, porque ellas han sido establecidas como un verdadero estatuto de garantías a favor del imputado y, por cierto, carecería de todo fundamento una interpretación que en definitiva restringiera una salvaguarda o protección que el propio ordenamiento jurídico ha dispuesto.

También puede invocarse como argumento a favor de la posición restrictiva que aquí se defiende, el hecho de que el artículo 456 bis del Código Penal establezca que las agravantes de alevosía y premeditación serán aplicables a los delitos de robo y hurto, en los casos en que se ejerciere violencia sobre las personas. Ello porque si fuera cierto que las agravantes mencionadas son aplicables a todos los delitos en que está comprometida la vida o la integridad física de las personas, cualquiera sea el lugar en que tales delitos aparezcan tipificados, la disposición del artículo 456 bis sería, francamente, superflua. En otras palabras, si fue necesario establecer una disposición como esa es, precisamente, porque los delitos de apropiación, aunque supongan el empleo de violencia, no quedan comprendidos dentro de la cláusula "delitos contra las personas".

Por último, en un sentido análogo al recién explicado, también podemos invocar ahora la disposición del artículo 368 bis del Código Penal, introducido por el número 3 del artículo $1^{\circ}$ de la Ley $\mathrm{N}^{\circ} 20.480$ (publicada el 18 de diciembre de 2010) que, como

41 Ramírez Guzmán, M. C., “Anteproyecto de Código Penal: hacia una racionalización de las circunstancias modificatorias de responsabilidad penal. El caso de las agravantes”, en Política Criminal, $\mathrm{N}^{\circ} 4$, 2007, pp. 1-22; Mera Figueroa, J., "De las circunstancias que agravan la responsabilidad criminal”, en Couso Salas, Hernández Basualto (Dir.): Código Penal comentado. Parte general, Santiago, Abeledo Perrot, pp. 311-312.

42 En este sentido, Mera Figueroa, J., "De las circunstancias que agravan la responsabilidad criminal”, cit., p. 312 . 
ya se explicó, hace aplicable la agravante de alevosía a algunos delitos de significación sexual. Antes de esa fecha se debatía arduamente sobre la posibilidad de incluir los delitos sexuales dentro de la categoría de delitos contra las personas, porque a pesar de que ellos atentan contra bienes jurídicos personalísimos, no están tipificados dentro del Título VIII del Libro II. Sin embargo, el hecho de que haya sido necesario contemplar una disposición como el artículo 368 bis, es claramente demostrativo de que lo determinante para formular aquella calificación no es la naturaleza del bien jurídico afectado, sino la ubicación que cada delito tiene asignada dentro del Código Penal ${ }^{43}$.

Las razones expuestas hasta aquí permiten afirmar que la circunstancia agravante de premeditación y la que consiste en el empleo de astucia, fraude o disfraz, ambas contempladas en el artículo 12, circunstancia 5ª , del Código Penal, en cuanto tienen vigencia solo respecto de los delitos contra la personas, no son aplicables a los delitos vinculados con la producción, difusión y almacenamiento de pornografía infantil, todos los cuales están tipificados dentro del Título VII del Libro II del Código Penal y no dentro del Título VIII, que se refiere, específicamente, a los delitos contra las personas ${ }^{44}$.

Por otra parte, pese a que las referencias legales a los delitos contra las personas en principio deberían incluir a todas las figuras delictivas contempladas en dicho título, el intérprete deberá dejar fuera aquellos delitos cuya fisonomía no tuviere relación alguna con los fundamentos de la agravante respectiva, como sucede, por ejemplo, con la alevosía respecto de los delitos contra el honor; o como ocurre, también, con esa misma agravante respecto de los delitos contemplados en el párrafo $5^{\circ}$ bis del título VIII del Código Penal, agregado por la Ley No 20.507, de 2011, en todas aquellas hipótesis que no impliquen un contacto directo entre el autor y la víctima.

\subsection{Precio, recompensa o promesa}

Como es sabido, el pago de una retribución (o la promesa de pago) a cambio de la ejecución de un delito puede traer consigo la aplicación de la circunstancia agravante de responsabilidad penal contemplada en el artículo $12 \mathrm{~N}^{\circ} 2$ del Código Penal.

La doctrina chilena ha debatido ampliamente sobre tres puntos relativos a esa circunstancia: a) el fundamento de la agravación; b) la naturaleza de la retribución prometida o entregada, y c) el carácter unilateral o bilateral de la figura, en el sentido de si ella es aplicable únicamente al autor material del delito o si, por el contrario, afecta también

${ }^{43} \mathrm{La}$ jurisprudencia no ha sido uniforme sobre este punto, si bien entendemos que durante los últimos diez años tiende a imponerse un criterio restrictivo, como el que aquí se defiende. Tal es el caso de un interesante fallo pronunciado por la Corte de Apelaciones de Santiago en el año 2003, en el cual se rechazó aplicar la agravante de alevosía tratándose del tipo de incendio con resultado muerte, argumentando que el título de castigo era un delito de incendio, que no está tipificado dentro de los "delitos contra las personas" (sentencia de 19 de mayo de 2003, Rol 5394-2003).

${ }^{44}$ Morillas Fernández, D., Análisis dogmático y criminológico de los delitos de pornografía infantil, cit., pp. 427-428, acepta la aplicabilidad de la agravante de disfraz, pero sobre la base de una realidad legislativa distinta a la nuestra. 
al mandante. Pero hay un punto que no ha sido suficientemente desarrollado por la doctrina nacional: concretamente, el ámbito de aplicación de la agravante que nos ocupa.

En contraposición a lo que ocurre con las agravantes de alevosía y premeditación, que expresamente restringen su campo de aplicación a los delitos contra la personas, la circunstancia que consiste en cometer el delito mediante precio, recompensa o promesa no contiene -al menos no de modo expreso- una limitación como la que se acaba de señalar. Sobre la base de este antecedente la doctrina establece que dicha agravante puede ser apreciada en cualquier clase de delitos. Pese a ello, un examen detenido del tenor literal del artículo $12 \mathrm{~N}^{\circ} 2$ y del contexto en que él se inserta, lleva a la conclusión contraria.

En efecto, al tipificar la alevosía el artículo $12 \mathrm{~N}^{\circ} 1$ utiliza el sintagma nominal "delito contra las personas", que tiene como núcleo el término delito y como especificativo del mismo, la cláusula contra las personas. Uno de los rasgos distintivos de esta clase de sintagmas es el hecho de operar como expansiones o proyecciones de su respectivo núcleo, dando lugar a una unidad de sentido, que es, en definitiva, la que desempeña las funciones sintácticas y es la que se relaciona o vincula con el resto de los componentes textuales ${ }^{45}$. Asimismo, es preciso tener en cuenta que la cobesión es una de las principales características de un texto y, al mismo tiempo, un elemento insoslayable frente a cualquier esfuerzo interpretativo respecto de sus términos; por su parte, la referencia, en cuanto se traduce en órdenes que señalan que debe recuperarse la información de otro segmento del discurso, es una de las relaciones cohesivas más destacadas, porque solo puede hablarse de cohesión textual en la medida en que se recupere el significado referencial, es decir, la identidad del objeto que se está significando ${ }^{46}$.

En el caso de un sintagma nominal, la necesidad de llevar a cabo una interpretación cohesiva de un determinado texto, impide centrar una referencia solo en el núcleo, porque él no expresa la identidad del objeto a que dicho sintagma se refiere. Así, en el caso del artículo 12 N 2 del Código Penal, el pronombre "lo" que sigue al verbo cometer, no puede estar referido a delito (que es el núcleo del sintagma contenido en el numeral anterior), sino a delito contra las personas, que es la cláusula que expresa su verdadero sentido. Por estas mismas razones, siendo este el sentido que corresponde atribuir a la remisión que efectúa el artículo $12 \mathrm{~N}^{\circ} 2$, si la voluntad legislativa hubiera sido extender la figura a cualquier clase de delito, tendría que haberlo consignado de modo expreso a través de cualquier medio discursivo que indicara al intérprete que la referencia debe entenderse hecha, no al sintagma en sí mismo (como unidad de sentido), sino a alguno de los elementos que lo constituyen.

Corrobora este planteamiento el hecho de que el artículo $12 \mathrm{~N}^{\circ} 3$ del Código Penal utilice la palabra delito sin especificaciones y sin hacer referencia a otra parte de la estructura textual en que dicha norma se inserta, porque si fue necesario hacerlo ello obedece a que indudablemente lo que se quiere significar es algo distinto a lo que figura en el

45 Real Academia Española de la Lengua: Nueva gramática de la lengua española, Madrid, 2009, 1.5.1.

${ }^{46}$ Ghio, E., Fernández, M. D.: Lingüistica sistémico-funcional. Aplicaciones a la lengua española, Ediciones UNL, Santa Fe, 2008, pp. 155-156. 
numeral precedente. En consecuencia, solo cabe concluir que la agravante de actuar mediante precio, recompensa o promesa tiene aplicación únicamente respecto de los delitos contra las personas, quedando excluida también la posibilidad de considerarla en los delitos de producción, difusión, adquisición y almacenamiento de pornografía infantil ${ }^{47}$.

\subsection{Trato ignominioso}

El artículo 12 circunstancia $9^{a}$ del Código Penal concede efecto agravatorio al hecho de emplear medios o hacer que concurran circunstancias que añadan la ignominia a los efectos propios del hecho.

Esta circunstancia posee, en realidad, un gran parecido con el ensañamiento. Al igual que este, se funda en una mayor ilicitud, basada en un incremento del desvalor de resultado $^{48}$. En el caso específico de la agravante que ahora nos ocupa, la mayor intensidad de lo injusto se vincula no con los efectos materiales del delito, sino con determinadas consecuencias morales que este puede producir.

Ignominia, en efecto, según el parecer prácticamente unánime de la doctrina, es una expresión que alude a determinadas ofensas que puede experimentar la víctima en su honor, entendiendo esta última expresión en un sentido subjetivo, es decir, referida a los sentimientos de propia estimación. De ahí que esta circunstancia resulte inaplicable en los delitos que tienden a la protección del bien jurídico aludido.

Tal afrenta ha de provenir de un hecho que no sea de aquellos que según las exigencias de cada tipo, ni según las modalidades concretas de comisión, sean inherentes al delito de que se trate. Aquella, por otra parte, tampoco ha de estar comprendida entre los resultados exigidos para la configuración del hecho delictivo. Estas exigencias emanan del requerimiento de que la ignominia se añada a los efectos propios del delito.

En general, parece existir consenso en orden a que la afrenta puede experimentarla tanto la víctima como un tercero, pero la jurisprudencia ha resuelto, acertadamente, que no se configura la agravante si el acto ignominioso tiene por objeto simplemente impedir que se descubra el delito o se castigue al delincuente ${ }^{49}$.

Si entendemos ignominia como sinónimo de escarnio, afrenta, deshonra, humillación u oprobio ${ }^{50}$, fácil será comprender que ella no solo resulta incompatible con los delitos que tienden a la tutela del honor, sino que también lo será con cualquier delito que implique una actuación en menosprecio de la víctima, como sucede, por ejemplo,

47 Morillas Fernández, D., Análisis dogmático y criminológico de los delitos de pornografía infantil, cit., pp. 430-431, acepta la aplicabilidad de esta agravante, pero sobre la base de una realidad legislativa distinta a la nuestra.

${ }^{48}$ En el mismo sentido, Cury, E., Derecho Penal., cit., p. 533, y Mera Figueroa, J., "De las circunstancias que agravan la responsabilidad criminal", cit., p. 334.

${ }^{49}$ En este sentido, sentencia de la Corte de San Miguel, de 13 junio de 1992 (RDJ, tomo 89, $2^{\mathrm{a}}$ parte, sec. $4^{\mathrm{a}}$, p. 156$)$.

${ }^{50}$ Estas son las relaciones conceptuales que suele establecer la doctrina nacional. Cfr., por todos, Mera Figueroa, J., “De las circunstancias que agravan la responsabilidad criminal”, cit., 334. 
en los delitos de significación sexual; y de modo mucho más elocuente en los delitos de producción, difusión, adquisición y almacenamiento de material pornográfico, en todos los cuales está presente la idea de utilización de un menor, la cual hace referencia a la más grave de los formas de trato ignominioso, que es la instrumentalización del ser humano.

En consecuencia, estando el desvalor de la ignominia incorporado en la descripción típica de los delitos vinculados con la pornografía infantil, solo cabe concluir que en este sector del ordenamiento punitivo no tiene vigencia la agravante que contempla el artículo 12, circunstancia $9^{a}$, del Código Penal.

\subsection{Abuso de confianza}

El artículo 12 circunstancia $7^{\mathrm{a}}$ del Código Penal concede efecto agravatorio al hecho de cometer el delito con abuso de confianza.

En relación con el significado del término confianza, se ha sostenido, acertadamente a nuestro juicio, que este debe ser entendido en un sentido amplio, representado por el sentimiento de seguridad de que uno no será objeto de agresiones delictuales de parte de una determinada persona. No está tomado, en consecuencia, en otras acepciones más restringidas, como podría ser la certeza acerca de la honorabilidad de cierto individuo o la admisión de una persona a la propia esfera de intimidad ${ }^{51}$.

El origen de esta situación de confianza no es siempre una relación jurídica. También cumplen con las exigencias de esta agravante una familiaridad de hecho e incluso un vínculo pasajero contraído en circunstancias que hagan esperar que se contará con la lealtad de un individuo. Por otra parte, del propio tenor de la norma se deduce con toda claridad que el delincuente ha de abusar de la confianza para la comisión del delito. En consecuencia, la circunstancia que nos ocupa no se configura si el hechor se vale de la confianza que en él ha depositado una persona para asegurar su impunidad o para obtener un aprovechamiento de los efectos provenientes del delito ${ }^{52}$.

El abuso de la confianza existe cuando el sujeto se aprovecha de ella para facilitar la comisión del delito, aunque no es estrictamente necesario que este modo de ejecución haya sido determinante para el éxito de la empresa criminal, pudiendo concurrir con otros. Pero en modo alguno puede estimarse que existe tal abuso si el delincuente ignora que cuenta con la confianza de la víctima.

Si bien es criterio mayoritario en la doctrina el que sostiene que esta circunstancia se funda en una mayor reprochabilidad, estimamos que, tal como ella figura en el texto de la ley, el criterio predominante en orden a su fundamentación es una mayor intensidad de lo injusto, representada por el empleo de un modo de ejecución especialmente reprobable, en cuanto sitúa a la víctima -merced a la confianza depositada en el hechor

51 Etcheberry, A., Derecho penal, II, cit., p. 30; Novoa, E., Curso de derecho penal chileno, cit., pp. 59-60.

52 En un sentido similar, Cury, E., Derecho Penal., cit., pp. 501-502. En un sentido diverso, Etcheberry, A., Derecho penal, cit., II, p. 30. 
y al consecuente debilitamiento de los resguardos del bien jurídico- en una verdadera situación de indefensión.

Aunque la relación de confianza en que se basa esta agravante implica un grado de interacción, o al menos de proximidad, entre autor y víctima, no cabe apreciar esta circunstancia en los delitos de difusión, adquisición y almacenamiento de material pornográfico infantil. Sí cabe apreciarla respecto del delito de producción de material pornográfico infantil, a condición de que concurran no solo los elementos que integran la agravante, sino también sus fundamentos ${ }^{53}$.

\section{CONCLusiones}

1. Para los efectos de examinar la aplicabilidad de los criterios de agravación de la pena en el ámbito de los delitos vinculados con la pornografía infantil es preciso efectuar una clara distinción entre las conductas que implican producción de material pornográfico infantil, por una parte, y las conductas que quedan encasilladas dentro de los conceptos de difusión, adquisición y almacenamiento de ese mismo material.

2. Las agravantes que contemplan los artículos 368 y 371 (relación de dependencia jurídica o moral de la víctima al autor) y en el artículo 368 bis (alevosía y pluralidad de autores) solo son aplicables al primer grupo de conductas indicadas en el acápite precedente. Por el contrario, no pueden ser aplicadas a las conductas del segundo grupo porque estas están tipificadas fuera del ámbito de aplicación de los artículos 368, 368 bis y 371 del Código Penal.

3. Siendo incontrovertible que la expresión delitos contra las personas alude exclusivamente a los delitos tipificados dentro del Título VIII del Libro II del Código Penal (porque así lo puso de manifiesto la propia incorporación del citado artículo 368 bis), forzoso es concluir que las agravantes de premeditación y la de empleo de astucia, fraude o disfraz no son aplicables a los delitos de producción, difusión, adquisición y almacenamiento de material pornográfico infantil.

4. Lo mismo cabe decir de la agravante de precio, recompensa o promesa que, por los términos en que aparece contemplada en el artículo 12 circunstancia $2^{\mathrm{a}}$ del Código Penal, solo resulta aplicable a los delitos contra la personas en sentido estricto.

5. Tampoco tiene aplicación respecto de los delitos que motivan estos comentarios la agravante que contempla el artículo 12, circunstancia 9ª del Código Penal, esto es, dispensar a la víctima un trato ignominioso, porque el desvalor de la ignominia está incorporado en la descripción típica de los delitos vinculados con la pornografía infantil.

53 En el mismo sentido, Morillas Fernández, D., Análisis dogmático y criminológico de los delitos de pornografía infantil, cit., pp. 432-433. 
6. Por último, en cuanto a la agravante de abuso de confianza que contempla el artículo 12 circunstancia $7^{a}$ del Código Penal, ella solo podría ser apreciada, aunque muy limitadamente, respecto del delito de producción de material pornográfico infantil, no así en los delitos de difusión, adquisición y almacenamiento de ese mismo material, porque el vínculo de confianza que podría existir entre el autor y la víctima carece de sentido como factor motivante de la ejecución de las conductas que configuran estos delitos.

\section{BiBLIOGRAFÍA}

Aguilar Aranela, C., Delitos sexuales, 2a edición, Editorial Metropolitana, Santiago, 2012.

Agustina, J., La pornografía. Sus efectos sociales y criminógenos, Editorial B de F, Buenos Aires, 2011.

Arias Eibe, M., "La circunstancia agravante de alevosía", en Revista Electrónica de Ciencia Penal y Criminología, 07-03, 2005.

Bullemore, V. y Mackinnon, J., Curso de Derecho Penal, LexisNexis, Santiago, 2005, tomo II.

Cox Leixelard, J. P., "Los delitos de producción, adquisición y tenencia maliciosa de material pornográfico como figuras expansivas del Derecho Penal", en Revista de Derecho de la Pontificia Universidad Católica de Valparaíso, N ${ }^{\circ}$ XXVI, 2005.

Cugat Mauri, M., "Prostitución y corrupción de menores e incapaces", en Álvarez García (dir.), Derecho penal español. Parte especial, Tirant lo Blanch, Valencia, 2011.

Cury, E., Derecho Penal. Parte General, 10ª edición ampliada, Editorial Universidad Católica de Chile, Santiago, 2011.

De la Fuente Jiménez, C., Delitos de pornografía infantil, Legal Publishing, Santiago, 2008.

De la Rosa Cortina, J. M., Los delitos de pornografía infantil. Aspectos penales, procesales y criminológicos, Tirant lo Blanch, Valencia, 2011.

Etcheberry, A., Derecho penal. Parte general, $3^{a}$ ed., Editorial Jurídica de Chile, Santiago, 2010, tomo II.

Garrido Montt, M., Derecho Penal. Parte especial, $4^{a}$ ed., Editorial Jurídica de Chile, Santiago, 2010.

GHio, E. y Fernández, M. D., Lingüistica sistémico-funcional. Aplicaciones a la lengua española, Ediciones UNL, Santa Fe, 2008.

Gracia Martín, L. y Vizueta Fernández, J., Los delitos de homicidio y de asesinato en el Código Penal español, Tirant lo Blanch, Valencia, 2007.

KüNSEmüller, C., “Delitos de pornografía infantil”, en Gaceta Jurídica, No 273, 2003.

Mera Figueroa, Jorge, "De las circunstancias que agravan la responsabilidad criminal”, en Couso Salas, Hernández Basualto (dir.): Código Penal comentado. Parte general, Santiago, Abeledo Perrot, 2011.

Molina Cantillana, R., Delitos de pornografía infantil, Librotecnia, Santiago, 2008.

Morales Prats, F. y García Albero, R., "Delitos contra la libertad e indemnidad sexuales", en Quintero Olivares (dir.), Comentarios a la parte especial del derecho penal, $9^{\mathrm{a}}$ ed. Aranzadi, Pamplona, 2011.

Morillas Fernández, D., Análisis dogmático y criminológico de los delitos de pornografía infantil, Dykinson, Madrid, 2005.

NovoA, E., Curso de derecho penal chileno. Parte general, $3^{\mathrm{a}}$ ed., Editorial Jurídica de Chile, Santiago, 2010.

OrTs Berenguer, E., "Delitos contra la libertad e indemnidad sexuales", en Vives Antón et al., Derecho penal. Parte especial. $3^{a}$ ed., Tirant lo Blanch, Valencia, 2010. 
Oxman Vilches, N., Libertad sexual y Estado de Derecho en Chile, Librotecnia, Santiago, 2007.

Politoff, S., Matus, J. P. y Ramírez, M. C., Lecciones de derecho penal. Parte especial, Editorial Jurídica de Chile, Santiago, 2005.

RaGuÉs i Vallès, R., "Delitos contra la libertad e indemnidad sexuales”, en Silva Sánchez (dir.): Lecciones de derecho penal. Parte especial. $3^{a}$ ed., Atelier, 2011.

Ramírez Guzmán, M. C., “Anteproyecto de Código Penal: hacia una racionalización de las circunstancias modificatorias de responsabilidad penal. El caso de las agravantes”, en Política Criminal, $\mathrm{N}^{\circ}$ 4, 2007.

Rodríguez Collao, L., "Honor y dignidad humana", en Revista de Derecho Pontificia Universidad Católica de Valparaíso, XX, 1999.

SÁINZ-Cantero Caparrós, J., "Delitos contra la libertad e indemnidad sexual”, en Morillas Cueva (coord.), Sistema de derecho penal español, parte especial, Dykinson, Madrid, 2011.

SÁnChez Pecarevic, C., Delito de almacenamiento de pornografía infantil, Librotecnia, Santiago, 2010.

Serrano Gómez, A. y Serrano Maíllo, A., Derecho penal. Parte especial. 16 a ed., Dykinson, Madrid, 2011.

SantibáÑez Torres, M. E. y Vargas Pinto, T., "Reflexiones en torno a las modificaciones para sancionar el femicidio y otras reformas relacionadas (Ley $\mathrm{N}^{\circ} 20.480$ )", en Revista Chilena de Derecho, 1 abril 2011, 38.

SuÁrez-Mira Rodríguez, C., Manual de Derecho Penal. Parte especial, Civitas, Madrid, 2006. 